\title{
STIMULATING EFFECT OF $\alpha$-ADRENOCEPTOR AGONISTS ON ISOPROTERENOL-INDUCED AMYLASE RELEASE IN RAT PAROTID TISSUE
}

\author{
Hideyo OHSHIKA, Haruo TAKEMURA, Junichiro ENDO, \\ Shinichi HATTA and Mamoru TANAKA \\ Department of Pharmacology. Sapporo Medical College. \\ Sapporo. llokkaido 060, Japan
}

Accepted August 31, 1981

\begin{abstract}
Isoproterenol (ISO)-induced amylase release from rat parotid slices was increased by the addition of methoxamine to either a normal or a calcium ( $\mathrm{Ca}$ )-free medium. The potentiating effect of methoxamine was completely blocked by the addition of phentolamine, irrespective of whether the slices were incubated in the normal or the Ca-free medium; and the effect also disappeared after prolonged preincubation $(60 \mathrm{~min}$ ) of the slices in the Ca-free medium. Both verapamil and procaine reduced methoxamine-induced amylase release, but only verapamil blocked the stimulating effect of methoxamine in the normal medium. ISO-induced accumulation of cyclic AMP in the slices was unaffected by methoxamine or phenylephrine. The results suggest a possibility that the potentiating effect of methoxamine on ISO-induced amylase release may be independent of the presence of extracellular $\mathrm{Ca}$ and the increased accumulation of cyclic AMP in the tissue is unnecessary.
\end{abstract}

In in vitro experiments, isoproterenol (ISO) causes a potent secretion of $\alpha$-amylase from rat parotid tissue through the activation of $\beta$ adrenoceptors $(1,2)$, and this effect is independent of the presence of calcium ( $\mathrm{Ca}$ ) in the incubation medium $(3,4)$. On the other hand, phenylephrine, a relatively selective $\alpha$-agonist, elicites a weak, but distinct, increase of amylase release which is dependent on the extraceilular $\mathrm{Ca}$ (2) through the activation of $\alpha$-adrenoceptors (2). Putney et al. (4) reported that stimulation of $\alpha$-adrenoceptors in parotid cells resulted in an increased $\mathrm{Ca}$ influx which is assumed as a possible cause for an increased amylase release (5).

From the above-mentioned facts, it must be predicted that in vitro ISO-induced amylase release would be enhanced by the addition of $\alpha$-agonists as a result of an increase of cyclic AMP level and $\mathrm{Ca}$ influx. However. it has been suggested that a concomitant stimulation of both $\alpha$ - and $\beta$-adrenoceptors in rat parotid tissue might cause a smaller amount of amylase release than that induced by a single stimulation of $\beta$-adrenoceptors (3). In addition, $\alpha$-agonists inhibited the ISOinduced accumulation of cyclic AMP by the increased entrance of extracellular $\mathrm{Ca}$ into the rat parotid tissue (6).

As the authors obtained results showing a stimulating effect of methoxamine on ISOinduced amylase release in rat parotid tissue. the present study was undertaken to investigate a possible role for $\mathrm{Ca}$ in the effect of the $\alpha$-agonist. 


\section{MATERIALS AND METHODS}

Incubation procedures: Male SpragueDawley rats weighing 180 to $220 \mathrm{~g}$ were used. Parotid glands were removed from the rats anesthetized with sodium pentobarbital (40 $\mathrm{mg} / \mathrm{kg}$, i.p.) and were cut into small pieces. Slices about $20 \mathrm{mg}$ in size were placed in a basket of nylon net, and then immersed in $5 \mathrm{ml}$ Krebs-Ringer-Tris (KRT) solution of the following composition (mM): $\mathrm{NaCl} 120.0$, $\mathrm{KCl} 5.0, \mathrm{MgCl}_{2}$ 1.2, $\mathrm{CaCl}_{2}$ 3.0, $\beta$-hydroxybutyrate sodium 5.0. Tris (hydroxymethyl)aminoethane 20.0, and the pH adjusted to 7.4 with $\mathrm{HCl}$.

The incubation of parotid slices was carried out by the procedure described by Leslie et al. (2). Briefly, the slices were equilibrated in $5 \mathrm{ml}$ KRT solution, aerated with pure oxygen for $25 \mathrm{~min}$ at $37 \mathrm{C}^{\circ}$, followed by transfer through three, $5 \mathrm{ml}$ volumes of KRT medium for 2. 10 and $10 \mathrm{~min}$ under the above-mentioned conditions. For incubation in the $\mathrm{Ca}$-free medium, $\mathrm{CaCl}_{2}$ was excluded from the composition of the normal KRT solution and $1 \mathrm{mM}$ ethylene glycol bis - (betaaminoethyl ether)-N,N'-tetraacetic acid (EGTA) was added (Ca-free KRT). The slices were treated with the normal KRT medium except during the second 10 min period when they were incubated in the Ca-free KRT solution with $1 \mathrm{mM}$ EGTA. In some experiments to investigate the influence of cellular $\mathrm{Ca}$ depletion on actions of secretagogues. slices were incubated in the Ca-free KRT with $1 \mathrm{mM}$ EGTA for 60 min prior to the successive three periods of incubation in the same $\mathrm{Ca}$ free medium.

ISO was added to the incubation media at the beginning of the second $10 \mathrm{~min}$ period. Methoxamine was added to the media throughout the first and the second $10 \mathrm{~min}$ periods. Phentolamine, verapamil, and procaine were added $2 \mathrm{~min}$ prior to the addition of methoxamine, and they were present throughout the incubation periods.

Determination of amount of released amylase: To measure the amount of amylase released into the media, $0.25 \mathrm{ml}$ aliquots were taken from each incubation medium immediately after the first and second $10 \mathrm{~min}$ incubation periods. Basal amylase release was determined at the end of the first $10 \mathrm{~min}$ incubation. After incubation, tissues were blotted on filter paper, weighed, and then homogenized in $5 \mathrm{ml} \mathrm{KRT}$ solution. A $0.25 \mathrm{ml}$ aliquot of the homogenate was used for assay of the enzyme activity. Amylase activity was assayed by the method of Bernfeld (7).

The net amount of released amylase was expressed as a percentage of the total amount of the enzyme initially contained in the tissue slices employing the following formula:

$$
S=\frac{M s-M b}{M s+T s}
$$

where $S$ is the percent release of total amylase, $\mathrm{Ms}$ is the amount of amylase in medium after incubation with secretagogues, $\mathrm{Mb}$ is the amount of amylase in basal release, and $T_{s}$ is the tissue content of amylase after incubation with secretagogues.

Measurement of cyclic AMP: To investigate the effects of $\alpha$-agonists on the tissue content of cyclic AMP, parotid slices were incubated with $\alpha$-agonists for $10 \mathrm{~min}$, followed by a 2 min incubation period with ISO in the presence of $\alpha$-agonists. After the incubation with ISO, tissues were immediately transferred into liquid nitrogen and were stored at $-20^{\circ} \mathrm{C}$ until the measurement of cyclic AMP. Cyclic AMP was measured by the radioimmunoassay technique of Honma et al. (8) using a commercial assay kit (Yamasa Shoyu Co.). Radioactivity of 125 was determined by a Packard auto-gamma scintillation counter (type 5130).

Analysis of data: Levels of significance were calculated using the Student's $t$-test. 
Drugs: Drugs used were: L-isoproterenol D-bitartrate (Sigma Chem.), L-phenylephrine $\mathrm{HCl}$ (Sigma Chem.), phentolamine mesylate (Regitin ${ }^{\circledR}$, Ciba Geigy), and procaine $\mathrm{HCl}$ (Sigma Chem.). Methoxamine $\mathrm{HCl}$ was kindly supplied by the Nippon Shinyaku Co. (Kyoto, Japan). Mexan ${ }^{\mathbb{B}}$ (methoxamine solution for injection. Nippon Shinyaku Co.) was used only in the experiment of ISOinduced accumulation of cyclic AMP. Verapamil was kindly supplied by the Eisai Co. (Tokyo, Japan). All drugs were used as a solution dissolved or diluted with KRT solution shortly before use.

\section{RESULTS}

Effects of methoxamine on 1SO-induced amylase release: The basal release of amylase from rat parotid slices during a $10 \mathrm{~min}$ incubation was $0.5 \pm 0.1 \%$ (of total amylase in the tissue) in the normal KRT medium and $0.3 \pm 0.1 \%$ in the Ca-free KRT medium.

During a $10 \mathrm{~min}$ incubation period with the normal KRT solution, amylase release from the slices was increased with increasing concentrations of ISO up to $1 \mathrm{mM}$, and the highest level reached was $20.3 \pm 1.6 \%$ of total amylase in the tissue (not shown). As shown in Table 1 , the rate of $10 \% \mathrm{M}$ ISOinduced release was markedly increased in the presence of $10 \mu \mathrm{M}$ methoxamine $(p<0.01)$. These potentiating effects of the $\alpha$-agonist was antagonized by the addition of $100 / \mathrm{M}$ phentolamine into the medium $(p<0.01)$.

In the Ca-free medium, the effects of ISO, both with and without methoxamine, were similar to the results in the normal KRT medium; and the potentiating effect of the $\alpha$-agonist on the 150 -induced release was completely blocked by the addition of phentolamine $(p<0.02)$ (Table 1). A similar result was obtained when phenylephrine was used as an $\alpha$-agonist in the Ca-free medium (not shown).

Effects of verapamil and procaine on

Table 1. Effects of methoxamine on isoproterenol (ISO)-induced amylase release in rat parotid slices

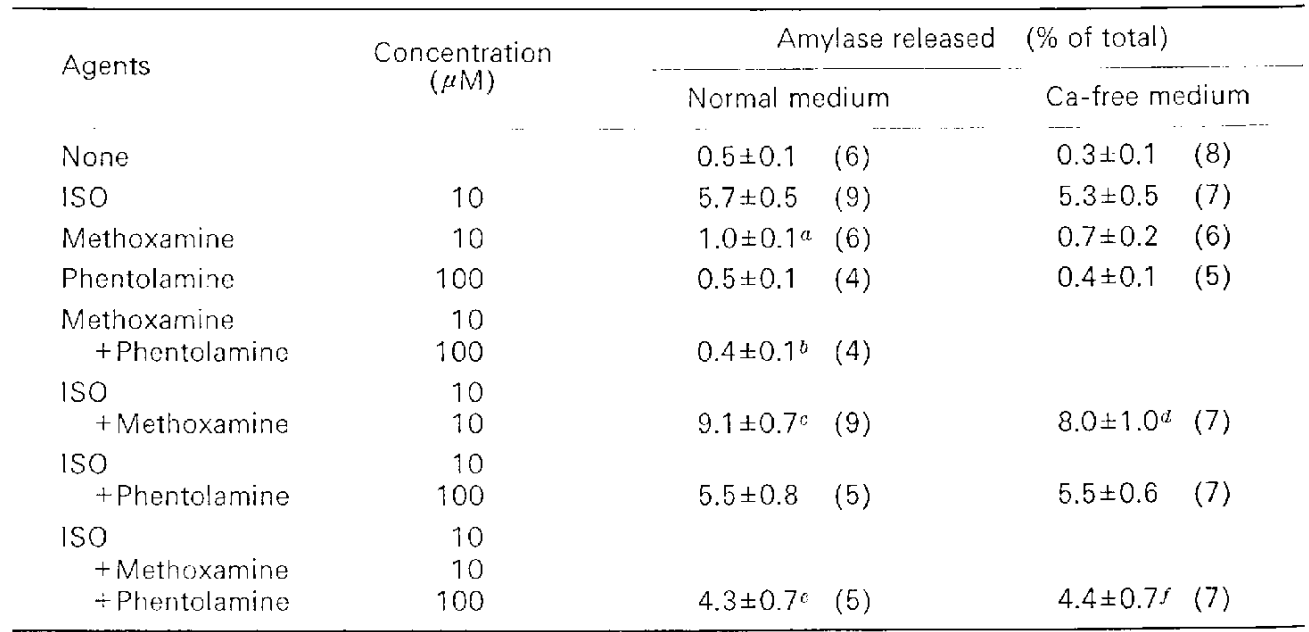

After preincubations with methoxamine and/or phentolamine, the second incubations wore carried out in the normal or the Ca-free and EGTA-added KRT media for $10 \mathrm{~min}$. Values are given as the mean $\pm S$.E. and the number of experiments is shown in parentheses. Statistical significance: $a_{p}<0.01$ compared to None: ${ }^{b} p<0.01$ compared to methoxamine alone: ${ }^{c} p<0.01 .{ }^{d} p<0.05$ compared to 150 alone; ${ }^{e} p<0.01, f_{p}<0.02$ compared to 150 plus methoxamine. 
amylase release from the parotid slices: To investigate the effect of $\mathrm{Ca}$ antagorists and local anesthetics on the potentiating effect of methoxamine, amylase release from the rat parotid tissue was examined in a medium to which verapamil $(100 \mu \mathrm{M})$ or procaine (1 mM) was added. Both verapamil and procaine had no effect on the basal and ISOinduced amylase release. As shown in Fig. 1, the increase in amylase release in response to a combination of 150 and methoxamine $(9.3 \pm 0.8 \%)$ was reduced by

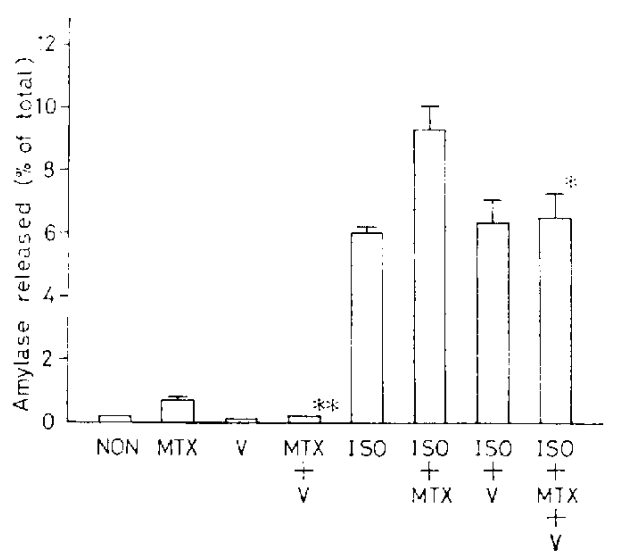

Fig. 1. Effects of verapamil on methoxamine- and isoproterenol-induced amylase release in rat parotid slices. Each column shows the mean value and vertical lines represent the S.E. $(n=6)$. " $p<0.01$ compared to methoxamine alone. " $p<0.05$ compared to methoxamine plus ISO. NON: no addition of drugs, ISO: $10 \mu \mathrm{M}$ isoproterenol, MTX: $10 \mu \mathrm{M}$ methoxamine, $V$ : $100 \mu \mathrm{M}$ verapamil. verapamil to the value obtained by ISO alone $(6.5 \pm 0.8 \%) \quad(p<0.05)$. On the contrary. procaine did not inhibit the enhancing effect of methoxamine on 1SO-induced response in spite of the fact that it decreased the effect of methoxamine alone (Fig. 2).

Effect of prolonged preincubation with Ca-free medium on amylase release: To clarify the role of intracellular $\mathrm{Ca}$ on the potentiation of ISO-induced amylase release by methoxamine, Ca-deprived slices of rat parotid were used. After preincubation with the Ca-free and EGTA-added KRT solution for $60 \mathrm{~min}$, the $1 S O$-induced amylase release

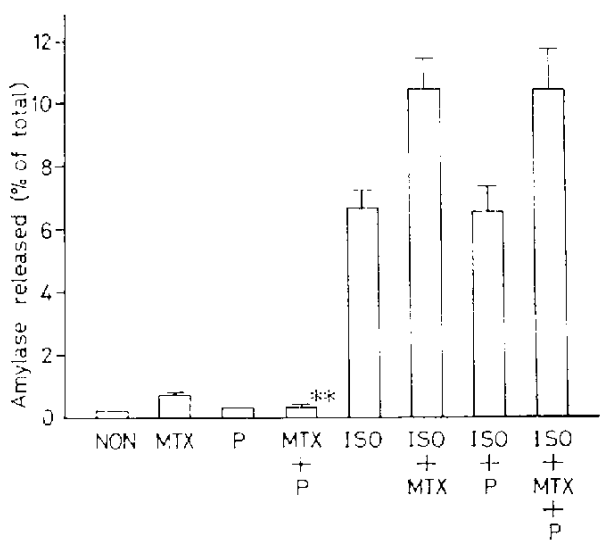

Fig. 2. Effects of procaino on methoxamine- and isoprotoronol-induced amylase release in rat parotid slices. Details are the same as shown in Fig. 1. except $1 \mathrm{mM}$ procaine $(P)$ was used. Number of exporiments was $6 .{ }^{*} p<0.01$ compared to methoxamine alone.

Table 2. Effect of a 60 min preincubation with $\mathrm{Ca}$-free and EGTAadded medium on isoproterenol (1SO)-induced amylase release in rat parotid slices

\begin{tabular}{lc}
\hline Agents & $\begin{array}{c}\text { Amylase released } \\
(\% \text { of total) }\end{array}$ \\
None & $0.3 \pm 0.0$ \\
ISO & $2.8 \pm 0.1$ \\
ISO+Methoxamine & $1.5 \pm 0.2^{* *}$ \\
\hline
\end{tabular}

The concentration of 150 and methoxamine were $10 \mu \mathrm{M}$. Values represent the meantS.E. $(n=6)$ of the percent release of total tissue amylase during a $10 \mathrm{~min}$ incubation with $\mathrm{Ca}$-free medium after preincubation. Statistical significance: ${ }^{*} \mathrm{p}<0.01$ compared to 150 . 
was approximately one half the release observed in normal KRT medium, with the potentiating effect of $10 \mu \mathrm{M}$ methoxamine being completely blocked under the same conditions (Table 2).

Effects of $\alpha$-agonists on 1SO-induced accumulation of cyclic AMP in rat parotid tissue: The content of cyclic AMP in rat parotid tissue was $0.73 \pm 0.11 \mathrm{pmol} / \mathrm{mg}$ tissue and was markedly increased to $21.00 \pm 1.80$ $\mathrm{pmol} / \mathrm{mg}$ tissue after $2 \mathrm{~min}$ of incubation with $10 \mu \mathrm{M}$ ISO. Methoxamine and phenylephrine $(10 \mu \mathrm{M})$ caused slight increases in the levels of cyclic AMP with values of $1.32 \pm 0.17$ and $1.27 \pm 0.17 \mathrm{pmol} / \mathrm{mg}$ tissue, respectively (Fig. 3). The ISO-induced accumulation of cyclic AMP was unaffected by pretreatment with $10 \mu \mathrm{M}$ methoxamine or phenylephrine.

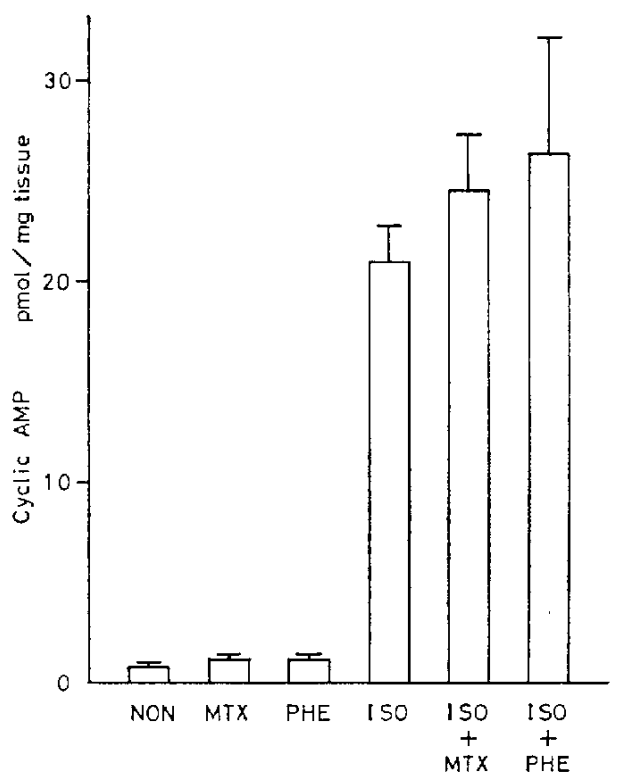

Fig. 3. Cyclic AMP accumulation induced by isoproterenol ( 150 ) in rat parotid tissue in vitro. Concentration of all drugs used were $10 \mu \mathrm{M}$. Vertical lines represent the S.E. $(n=5)$. Samples for the cyclic AMP assay were collected at the end of a 2 min incubation after addition of ISO. Abbrevations used are: NON, no addition of drugs: MTX, methoxamine; PHE, phenylephrine.

\section{DISCUSSION}

In the present study, a combination of an $\alpha$-agonist methoxamine and a $\beta$-agonist ISO resulted in a superadditive effect on the release of amylase from the rat parotid slices in the normal incubation medium, and this increased release was recovered by phentolamine to the level induced by 150 alone (Table 1). It has been postulated that, unlike ISO $(4,9), \alpha$-agonists and muscarinic agents might cause amylase release due to the increased entrance of extracellular $\mathrm{Ca}$ into the parotid cells $(2,4,5)$. However. as shown in Table 1 , the $\alpha$-agonist itself elicited the amylase release as Leslie et al. reported (2), and this effect did not disappear even under Ca-free conditions. Prolonged incubation in the Ca-free medium probably produces a loss of its activity to induce the enzyme release. In fact, it has been reported that the effects of carbachol or phenylephrine on the transit efflux of ${ }^{86} \mathrm{Rb}$ in rat parotid cells, depending on the intracellular $\mathrm{Ca}$, were obviously influenced by the length of preincubation in the $\mathrm{Ca}$-free medium (10. 11).

The increase of $\mathrm{Ca}$ entrance probably is not responsible for the enhancement of ISOinduced response by methoxamine (and phenylephrine) since this stimulating effect of $\alpha$-agonists occurred in the $\mathrm{Ca}$-free medium as well as in the normal medium (Table 1). This assumption may be supported by the following evidence: (i) A23187, a divalent cation ionophore, did not increase the ISOinduced amylase release in the presence of extracellular $\mathrm{Ca}$ (4, 12): (ii) carbachol decreased $1 \mathrm{SO}$-induced amylase release from isolated parotid cells (13): (iii) the effective concentration of epinephrine for amylase release is 10 to 100 times lower than that for potassium release (3).

The results shown in Figs. 1 and 2 on the effect of verapamil and procaine may be 
explained by their blocking actions on the transmembrane $\mathrm{Ca}$ fluxes such that reported in smooth muscles and cardiac tissue (14). However, evidence showing the possibility that verapamil could bind to $\alpha$-adrenoceptors and would block the action of $\alpha$-agonists, has been obtained in experiments using rat brain tissue $(15,16)$ and rat liver cells (17). In addition, it was suggested in some studies that verapamil may inhibit the utilization of the intracellular $\mathrm{Ca}(18,19)$. The discrepancy observed in the inhibitory effects of verapamil and procaine might have resulted from a difference in their binding capacities on $\alpha$ adrenoceptors causing a blockade of the receptors (16), or a difference between their blocking activities towards the mobilization of intracellular Ca from its storage sites (20). The exact mechanism through which the drug actions observed in the present study occur may be decided by further investigations on Ca fluxes, effect of increased extracellular $\mathrm{Ca}$, and radioligand binding to $\alpha$-adrenoceptors in the presence of both methoxamine and verapamil or procaine.

As shown in Table 2, the stimulating action of methoxamine on ISO-induced amylase release completely disappeared in the Ca-depleted tissue produced by preincubation with the Ca-free medium for $60 \mathrm{~min}(10,11)$. There is an interesting report that the stimulation of $\alpha$-adrenoceptors localized on the cellular surface probably causes the intracellular mobilization of $\mathrm{Ca}$ from its storage sites in hepatic cells (21). Therefore, it seems likely that the present results (Tables 1, 2 and Figs. 1, 2) may represent a possibility for mobilization of intracellular Ca by $\alpha$-agonists.

If the enhanced response of 150 caused by $\alpha$-agonists was not due to the increase of $\mathrm{Ca}$ influx, this effect of $\alpha$-agonists might be due to an elevation of the cyclic AMP level in parotid cells, in a way similar to what was indicated in hepatic cells by Blackmore et al.
(22). However, ISO-induced increase of cyclic AMP was not enhanced by $\alpha$-agonists in our experiment. Oron et al. (6) has reported an inhibitory effect of methoxamine and carbachol on 15O-induced accumulation of cyclic AMP, but did not refer to the change of amylase release. ISO-induced amylase release is reduced by carbachol (13) which may rapidly inhibit ISO-induced increase of cyclic AMP (6). Further study is necessary to resolve whether or whether not methoxamine has a biphasic effect on ISOinduced amylase release. The discrepancy shown in two individual experiments may have resulted from differences in the lengths of the preincubation times or compositions of the media. The above results, at least, suggest that an increase of cyclic AMP content may not be essential for the stimulating effect of the $\alpha$-agonist on ISO-induced amylase release.

The present results suggest that the potentiating effect of methoxamine on ISOinduced amylase release may be independent of the presence of extracellular $\mathrm{Ca}$ and the increased accumulation of cyclic AMP in the tissue.

Acknowledgement: This work was supported in part by the Ministry of Education, Science and Culture, Japan (Scientific Research 1980, 5670033).

\section{REFERENCES}

1) Batzri, S., Selinger, Z. and Schramm, M.: Potassium ion release and enzyme secretion: Adrenergic regulation by $\alpha$ - and $\beta$-receptors. Science 174, 1029-1031 (1971)

2) Leslie, B.A., Putney, J.W., Jr. and Sherman, J.M.: $\alpha$-Adrenergic, $\beta$-adrenergic and cholinergic mechanisms for amylase secretion by rat parotid gland in vitro. J. Physiol. 260, 351-370 (1976)

3) Batzri, S. and Selinger, Z:: Enzyme secretion mediated by the epinephrine $\beta$-receptor in rat parotid slices. Factors governing efficiency of the process. J. biol. Chem. 248, 356-360 (1973) 
4) Putney, J.W., Jr., Weiss, S.J., Leslie, B.A. and Marier, S.H.: Is calcium the final mediator of exocytosis in the rat parotid gland? J. Pharmacol. exp. Ther. 203, 144-155 (1977)

5) Butcher, F.R.: The role of calcium and cyclic nucleotides in $\alpha$-amylase release from slices of rat parotid: Studies with the divalent cation ionophore A-23187. Metabolism 24, 409-418 (1975)

6) Oron, Y., Kellogg. J. and Larner, J.: Alpha adrenergic and cholinergic-muscarinic regulation of adenosine cyclic $3^{\prime} .5^{\prime}$-monophosphate lcvels in the rat parotid. Mol. Pharmacol. 14, 1018-1030 (1978)

7) Bernfeld, P.: Methods in Enzymology, Edited by Colowick, S. P. and Kaplan, N.O., Vol. 1, p. 149158, Academic Press. New York (1955)

8) Honma, M., Satoh, T., Takezawa, J. and Ui, M.: An ultrasensitive method for the simultaneous determination of cyclic AMP and cyclic GMP in small volume samples from blood and tissue. Biochem. Med. 18, 257-273 (1977)

9) Koelz, H.R., Kondo, S., Blum, A.L. and Schulz, l.: Calcium ion uptake induced by cholinergic and $\alpha$-adrenergic stimulation in isolated cells of rat salivary glands. Pflügers Arch. 370, 37-44 (1977)

10) Putney, J.W., Jr.: Biphasic modulation of potassium release in rat parotid gland by carbachol and phenylephrine. J. Pharmacol. exp. Ther. 198, 375-384 (1976)

11) Butcher, F.R.: The calcium requirement for stimulation of rubidium efflux from isolated rat parotid acinar cells by carbachol. Life Sci. 24, 1979-1982 (1979)

12) Selinger, Z., Eimerl, S. and Schramm, M.: $A$ calcium ionophore stimulating the action of epinephrine on the adrenergic receptor. Proc. natn. Acad. Sci. U.S.A. 71, 128-131 (1974)

13) Takemura, H., Ohshika, H. and Tanaka, M.: Potentiating effects of $\alpha$-adrenergic agonists on isoproterenol-induced amylase release in isolated rat parotid cells. Japan. J. Pharmacol. Supp. (1981) (in press)
14) Fleckenstein, A.: Ann. Rev. Pharmacol. Toxicol., Edited by Elliott, H.W., George, R. and Okun, R., Vol. 17, p. 149-166. Annual Reviews Inc. Palo Alto (1977)

15) Glossmann, H. and Hornung, R.: Calcium- and potassium-channel blockers interact with $\alpha$ adrenoceptors. Mol. Cell. Endocrinol. 19, 243251 (1980)

16) Fairhurst, A.S., Whittaker, M.L. and Ehlert, F.J.: Interactions of D600 (methoxyverapamil) and local anesthetics with rat brain $\alpha$-adrenergic and muscarinic receptors. Biochem. Pharmacol. 29, 155-162 (1980)

17) Blackmore, P.F., El-Refai, M.F. and Exton, J.H.: $\alpha$-Adrenergic blockade and inhibition of A23187 mediated $\mathrm{Ca}^{2+}$ uptake by the calcium antagonist verapamil in rat liver cells. Mol. Pharmacol. 15, 598-606 (1979)

18) Kondo, K., Suzuki, T., Okuno, T., Suda, M. and Saruta, T.: Effects of nifedipine, diltiazem and verapamil on the vasoconstrictor responses to norepinephrine and potassium ions in the rat mesenteric artery. Archs int. Pharmacodyn. Thér. 245, 211-217 (1980)

19) Church, J. and Zsoter, T.T.: Calcium antagonistic drugs. Mechanism of action. Canad. J. Physiol. Pharmacol. 58, 254-264 (1980)

20) Rahwan, R.G., Borowitz, J.L. and Miya, T.S.: The role of intracellular calcium in catecholamine secretion from the bovine adrenal medulla. J. Pharmacol. exp. Ther. 184, 106-118 (1973)

21) Dehaye, J.-P., Blackmore, P.F., Venter, J.C. and Exton, J.H.: Studies on the $\alpha$-adrenergic activation of hepatic glucose output. $\alpha$ Adrenergic activation of phosphorylase by immobilized epinephrine. J. biol. Chem. 255, 3905-3910 (1980)

22) Blackmore, P.F., Assimacopoulos-Jeannet, F., Chan, T.M. and Exton, J.H.: Studies on $\alpha$ adrenergic activation of hepatic glucose output. Insulin inhibition of $\alpha$-adrenergic and glucagon actions in normal and calcium-depleted hepatocyte. J. biol. Chem. 254, 2828-2834 (1979) 